\title{
Monitoring $\mathrm{pH}$ in corrosion engineering by means of thermally-produced iridium oxide electrodes
}

\author{
Yurena Seguí Femenias ${ }^{a, *}$, Ueli Angst ${ }^{a}$, Bernhard Elsener ${ }^{a, b}$
}

a ETH Zürich, Institute for Building Materials (IfB), Stefano-Franscini-Platz 3, 8093 Zurich, Switzerland

b University of Cagliari, Department of Chemical and Geological Sciences, 09100 Monserrato (CA), Italy

*Corresponding author: Phone: +41 4463376 68, Email: syurena@ethz.ch

\section{Abstract:}

A pH sensor to be used in highly alkaline media under continuous long-term immersion conditions is crucial in various engineering applications. This work develops the production protocol and posterior conditioning of thermally oxidized iridium $\left(\mathrm{IrO}_{\mathrm{x}}\right)$ electrodes to be used as potentiometric $\mathrm{pH}$ sensors embedded in highly alkaline environments such as concrete or cathodically protected steel in soil. The main investigated aspects for the desired applications are the potential-pH response, its reproducibility, accuracy, and oxygen dependency. The stability during long-term immersion is also studied in detail. The studied $\mathrm{IrO}_{\mathrm{x}}$ electrodes responded to $\mathrm{pH}$ changes with slopes between -50 and -68 $\mathrm{mV} / \mathrm{pH}$ unit, even after continuous immersion in alkaline solutions for almost 2 years. Additionally, the electrodes response did not show oxygen dependency. Our results highlight the importance of sufficient conditioning in alkaline media prior to use. When properly produced, conditioned, and pre-calibrated the electrodes reproducibly permit measuring the $\mathrm{pH}$ with a maximum error of $0.5 \mathrm{pH}$ units over a range of at least $\mathrm{pH} 9$ to 13.5 . Preliminary results show that the studied electrodes are promising sensors for monitoring $\mathrm{pH}$ changes in concrete.

Keywords: thermally oxidized iridium $\mathrm{pH}$ sensor, potential-pH response, alkaline environment, long-term stability, reinforcing steel corrosion in concrete, cathodic protection in soil. 


\section{Introduction}

The $\mathrm{pH}$ (negative logarithm of the $\mathrm{H}^{+}$activity) is one of the most important parameters in many fields, from life science (biological, environmental, medical) to engineering (civil, nuclear, energy) [1-6]. Therefore, many different electrochemical and non-electrochemical techniques have been developed for measuring the $\mathrm{pH}$ [7].

Applications in corrosion engineering require permanent long-term monitoring of $\mathrm{pH}$ (in the order of years) in highly alkaline media ( $\mathrm{pH}$ up to 13.5). In these applications, long-term stability of the method is of outmost importance. On the other hand, as the processes leading to a change in $\mathrm{pH}$ are relatively slow, the requirements to sensor response time are far less strict than in analytical chemistry.

The most important corrosion engineering application for in-situ long-term $\mathrm{pH}$ measurement is steel reinforced concrete, which is the most used construction material world-wide. In the highly alkaline pore solution of concrete ( $\mathrm{pH} 12.5$ - 13.5), steel is protected from corrosion by the formation of an oxide layer (passive film). Due to the reaction of alkaline components in the concrete pore solution with $\mathrm{CO}_{2}$ from the atmosphere, a process called carbonation, the $\mathrm{pH}$ decreases to levels lower than $9[8,9]$ and the steel reinforcement is depassivated. In presence of oxygen and humidity, corrosion of the reinforcement occurs, leading to loss of durability and finally structural deterioration [8]. Therefore, knowledge of the $\mathrm{pH}$ in the concrete is essential. The different methods tested and used for $\mathrm{pH}$ measurements in concrete are presented in a recent review [10]. From this review, it emerges that most of the available methods are destructive, time consuming, and do not allow continuous $\mathrm{pH}$ monitoring. Regarding the latter, fibre optic sensors were tested but showed serious limitations such as chemical instability at high $\mathrm{pH}$, dye leaching, and short life span. Embedded potentiometric electrodes based on several metal oxides for measuring $\mathrm{pH}$ in concrete were also studied. Among them, iridium/iridium oxide electrodes $\left(\mathrm{IrO}_{\mathrm{x}}\right)$ were the most promising [11].

Iridium/iridium oxide electrodes have been reported perform well in aqueous solutions over wide range of $\mathrm{pH}$ and temperature $[1,6,12-17]$. Preparation methods of $\mathrm{IrO}_{x}$ electrodes include electrochemical deposition [12-14,18], sputtering deposition [3], sol-gel processes $[15,16]$, and electrochemical $[1,14]$ or thermal oxidation $[17,19,20]$. Table 1 collects the main features of iridium oxides electrodes reported in literature.

Table 1 Influence of the production method on oxide thickness, hydrous/anhydrous oxide, potential$\mathrm{pH}$ slope, and response time, together with the longest immersion time and tested $\mathrm{pH}$-range of iridium oxide electrodes reported in literature. 


\begin{tabular}{cccccccc}
\hline & $\begin{array}{c}\text { thickness } \\
(\mathbf{n m})\end{array}$ & Anhydrous & $\begin{array}{c}\text { slope } \\
(\mathbf{V} / \mathbf{p H} \text { unit })\end{array}$ & time $(\mathbf{s})$ & immersion & pH-range \\
\hline \multirow{3}{*}{ Sol-gel } & $\approx 400$ & Anhydrous & $\approx-0.051$ & $<2$ & $<1$ day & $\approx 1.5-12$ & {$[15]$} \\
\cline { 2 - 7 } & $400-600$ & Anhydrous & $\approx-0.071$ & $\approx 6$ & $<1$ day & $\approx 3-11$ & {$[16]$} \\
\cline { 2 - 7 } & -- & Anhydrous & $\approx-0.059$ & $<10$ & $<1$ day & $\approx 1-13$ & {$[21]$} \\
\hline $\begin{array}{c}\text { Electrochem. } \\
\text { oxidation }\end{array}$ & - & Hydrous & $\approx-0.047$ & $<60$ & 10 days & $\approx 2-12$ & {$[1]$} \\
\hline Sputtering & $\approx 100$ & Anhydrous & $-0.060 \div-0.055$ & - & $<1$ day & $\approx 2-12$ & {$[23]$} \\
\hline \multirow{2}{*}{$\begin{array}{c}\text { Electrochem } \\
\text { deposition }\end{array}$} & -- & Hydrous & $-0.070 \div-0.064$ & $\approx 30$ & $<1$ day & $\approx 2-12$ & {$[24]$} \\
\cline { 2 - 7 } & 3500 & Hydrous & $-0.084 \div-0.070$ & $<60$ & $<1$ day & $\approx 2-12$ & {$[13]$} \\
\hline $\begin{array}{c}\text { Thermal } \\
\text { oxidation }\end{array}$ & 2000 & Hydrous & $-0.080 \div-0.060$ & $\approx 60$ & 5 days & $\approx 2-11$ & {$[14]$} \\
\hline
\end{tabular}

${ }^{*}$ the electrodes were tested several times up to an age of 2.5 years; the immersion times were $2-10$ days

From Table 1 it emerges that most studies were performed in research works of analytical chemistry, thus in solutions with $\mathrm{pH}<12$ and with relatively short immersion times in the order of days; the longest immersion time was in fact 10 days $[1,17,19,20]$. The differences in potential $\mathrm{pH}$ response reported in literature (Table 1) were usually associated to differences in structure and composition of the oxide layer depending on the fabrication methods [25]. In this work, thermally oxidized iridium oxide $\left(\mathrm{IrO}_{\times}\right)$electrodes were prepared and tested as potentiometric $\mathrm{pH}$ sensors in highly alkaline solutions ( $\mathrm{pH}$ between 9 and 13.5) up to almost 2 years of immersion times. The main features studied are the response to $\mathrm{pH}$ changes, together with the reproducibility and accuracy of the potential response for the individual $\operatorname{IrO}_{x}$ electrodes. The influence of the oxygen content in solutions and the long-term stability when continuously immersed in alkaline solution were also studied.

\section{Materials and methods}

\subsection{Materials and solutions}

For the preparation of the $\mathrm{IrO}_{\mathrm{x}}$ electrodes (section 2.2), iridium wires $(0.5 \mathrm{~mm}$ diameter, $99.9 \%$ purity) and gold wires (0.25 mm diameter, $99.99 \%$ purity) were obtained from Goodfellow, lithium carbonate (anhydrous powder, purity >99\%) from Alfa Aesar, and epoxy coating (ASTORIT PUR 105) from Astorit.

Exposure solutions were prepared by mixing defined amounts of orthoboric acid $\left(\mathrm{H}_{3} \mathrm{BO}_{3}\right)(\geq$ 99.5\%, Sigma-Aldrich) and sodium hydroxide ( $\geq 99.5 \%$, Merck KGaA) with de-ionized water (conductivity $\approx 2 \mu \mathrm{S} / \mathrm{cm}$ ). The $\mathrm{pH}$ of the solutions was periodically measured with a standard glass cell $\mathrm{pH}$ electrode with silver-silver chloride $(\mathrm{Ag} / \mathrm{AgCl})$ reference electrode. The $\mathrm{pH}$ 
values of the solutions and the concentrations of orthoboric acid and sodium hydroxide used for their preparation are listed in Table 2.

Table $2 \mathrm{pH}$ values of the four solutions prepared for the potentiometric measurements, together with the concentrations of orthoboric acid $\left(\mathrm{H}_{3} \mathrm{BO}_{3}\right)$ and sodium hydroxide used for their preparation.

\begin{tabular}{cccc}
\hline Solution & $\begin{array}{c}\text { Concentration } \mathrm{H}_{3} \mathrm{BO}_{3} \\
\left(\mathbf{m o l} \cdot \mathbf{L}^{-1}\right)\end{array}$ & $\begin{array}{c}\text { Concentration } \mathbf{~ N a O H} \\
\left(\mathbf{m o l} \cdot \mathbf{L}^{-1}\right)\end{array}$ & $\begin{array}{c}\text { Measured pH after } \\
\text { production (at 20 }\end{array}$ \\
\hline Borate 1 & 0.50 & 0.30 & 9.3 \\
\hline Borate 2 & 0.50 & 0.48 & 10.6 \\
\hline Borate 3 & 0.05 & 0.60 & 11.9 \\
\hline Borate 4 & 0.05 & 1.20 & 13.5 \\
\hline
\end{tabular}

\subsection{Preparation of the $\mathrm{IrO}_{\mathrm{x}}$ electrode}

Iridium metal wires (0.5 mm diameter and $10-15 \mathrm{~mm}$ length) were ultrasonically cleaned in 6 $\mathrm{mol} \cdot \mathrm{L}^{-1} \mathrm{HCl}$ solution for 10 minutes and afterwards washed with de-ionized water (conductivity $\approx 2 \mu \mathrm{S} / \mathrm{cm}$ ) for 10 minutes to ensure that no impurities were left on the wires surface. The wires were then dried in air at $20^{\circ} \mathrm{C}$ and positioned in a ceramic crucible lined with a gold foil and covered with lithium carbonate on both sides. They were then heated up to $870^{\circ} \mathrm{C}$ in 3 hours in a furnace (Nabertherm, model B180) under air atmosphere, maintained at $870{ }^{\circ} \mathrm{C}$ for 5 hours and cooled down. A fast ( 1 hour) and a slow (14 hours) cooling process were investigated. In the fast cooling process the crucible with the sample was taken out from the furnace; in the slow cooling process the crucible with the oxidized Ir wires was left inside the furnace until ambient temperature $\left(20-21^{\circ} \mathrm{C}\right)$ was reached. In both cases, the cooling process had an asymptotic behaviour with respect to time. For the fast cooling, the sample needed $20 \mathrm{~min}$ to cool down to half of the oxidation temperature $\left(870^{\circ} \mathrm{C}\right)$, whereas for the slow cooling time, 2 hours were needed.

Once reached room temperature, the solid carbonate in the crucible was dissolved with 6 $\mathrm{mol} \cdot \mathrm{L}^{-1} \mathrm{HCl}$ solution. Two different cleaning procedures were then investigated in order to remove any attached soluble components and to ensure that there was no chloride left on the electrodes surface: a) 10 min ultrasonic cleaning in de-ionized water and b) several times careful rinsing with de-ionized water. As a result, a black oxide layer was formed on the surface of the iridium wires. Information regarding the mechanism of metal oxide film growth in carbonate melt can be found in literature [17,19,26,27]. To remove the water not bound to the oxide layer formed, the cleaned wires were heated up to $120^{\circ} \mathrm{C}$, maintained at that temperature for 11 hours and cooled down inside the furnace until they reached ambient temperature (approximately 10 hours). A small area at the end of the oxidized wire was then scraped off until pure iridium was exposed. A thin gold wire $(0.25 \mathrm{~mm}$ diameter and approximately $5 \mathrm{~mm}$ length) was tightly wrapped around the exposed iridium and fixed with 
crimping pliers to form a good physical and electrical connection. Finally, an epoxy coating was applied to cover the area of the exposed iridium and gold connection to provide electric insulation. Epoxy coating was also applied on the tip of the electrode because it was suspected that some adherence problems of the $\mathrm{IrO}_{x}$ could happen on the edges. $\mathrm{A}$ schematic representation and stereomicroscopy image of the $\mathrm{IrO}_{\mathrm{x}}$ electrode produced and used in this study is shown in Fig. 1.

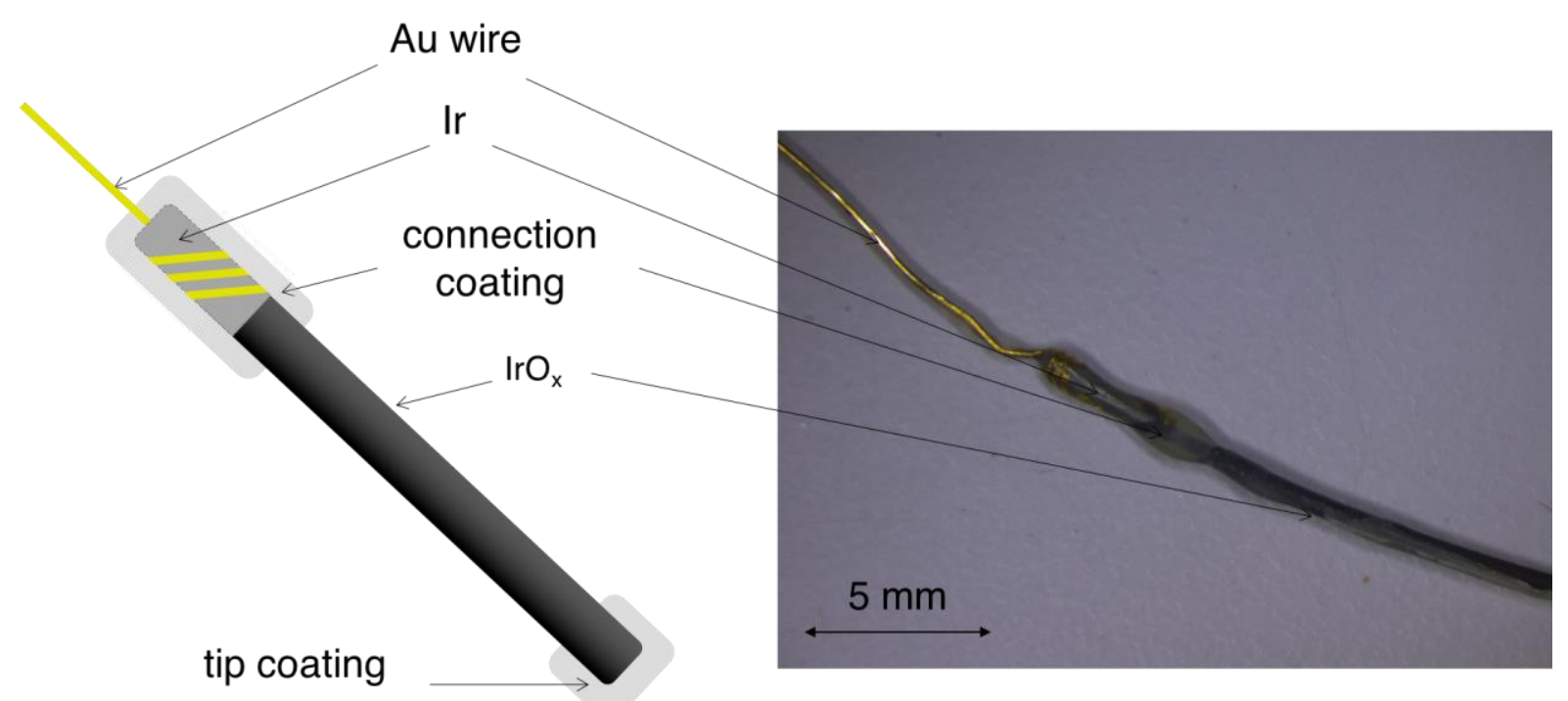

Fig. 1 Schematic representation and stereomicroscopy image of the $\mathrm{IrO}_{\mathrm{x}}$ electrode produced and used in this study.

In total, 8 different batches (denoted I-VIII) of three to nine $\mathrm{IrO}_{x}$ electrodes (denoted 1-n for each batch) were produced. This production procedure is based on the one reported in $[17,19]$. However, we modified the cooling and cleaning processes.

\subsection{Microscopic Characterization of the $\mathrm{IrO}_{x}$ electrodes}

Selected $\mathrm{IrO}_{\mathrm{x}}$ wires were cast in epoxy and the cross section was polished. Optical and scanning electron microscopy (SEM) was performed. Based on the backscattered electron SEM images, the thickness and the percentage of pores (porosity) of the oxide layer formed on the iridium wires were determined.

The average and standard deviation of the oxide layer thickness was obtained from ten measurements.

The oxide porosity was defined as the percentage of pores (black spots in the SEM image) of the oxide layer (grey area in the SEM image). The SEM images were analysed with the GIMP image analysis software, which enables to adjust the black / white contrast of the image selected and to quantify the pore area (black area). The percentage of pores of the 
oxide layer was then calculated as the average of five image analyses of $20-30 \mu \mathrm{m}$-long areas of the oxide layer.

\subsection{Set-up and instruments for the potentiometric measurements}

The potential $E$ of the $\mathrm{IrO}_{x}$ electrodes produced was measured versus a silver/silver chloride/saturated potassium chloride $(\mathrm{Ag} / \mathrm{AgCl} / \mathrm{sat} . \mathrm{KCl})$ reference electrode $(+0.197 \mathrm{~V}$ versus the Standard Hydrogen Electrode, SHE). A Luggin capillary (filled with the test solution) was used when the reference electrode was immersed in the test solution to avoid contamination of the test solution with $\mathrm{KCl}$ and of the reference electrode with the test solution. The set-up is schematically depicted in Fig. 2.

The liquid junction potential established when immersing the reference electrode in the test solution was estimated to maximum $5 \mathrm{mV}$ for the $\mathrm{pH}$ values considered in this study [28] and was thus neglected.

The measurements were performed with a Keithley multimeter and multiplexer (Keithley Instruments Inc.) connected to a computer for data acquisition, which allowed recording the potential of several $\mathrm{IrO}_{\mathrm{x}} \mathrm{vs}$. the reference electrode over time. All the experiments were carried out at room temperature $\left(20-21^{\circ} \mathrm{C}\right)$.

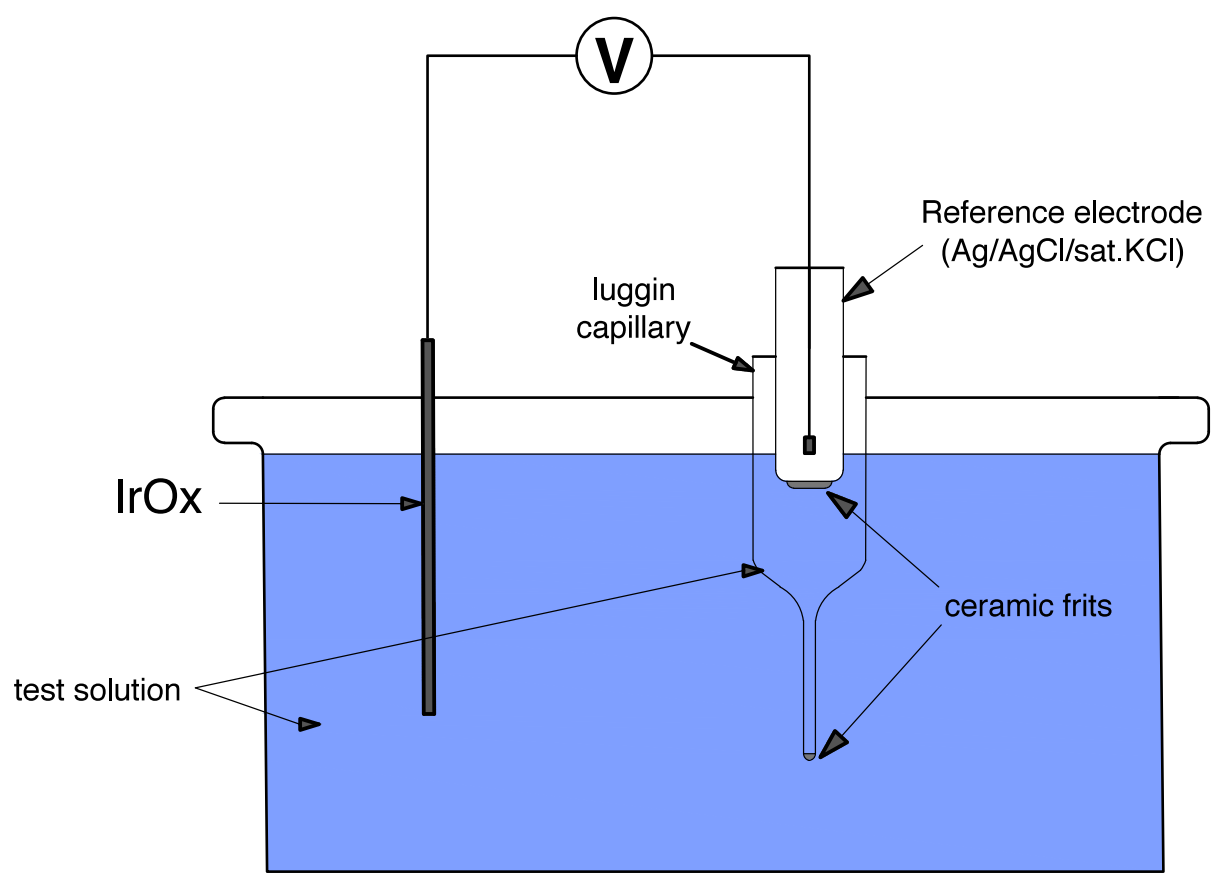

Fig. 2 Set-up for the potentiometric measurements of the $\mathrm{IrO}_{x}$ electrodes. 


\subsection{Measurement procedures}

\subsubsection{Determination of potential-pH response}

After production, the $\mathrm{IrO}_{\mathrm{x}}$ electrodes were immersed in one of the 4 test solutions used (Table 2). The exposure solution was changed several times in order to investigate the influence of the $\mathrm{pH}$ exposure history on the final potential-pH response. These $\mathrm{pH}$ exposure variations lasted between 2 and 6 months. After this, the exposure solution was exchanged to $\mathrm{pH} \approx 13.5$ and the potential-pH response of the produced $\mathrm{IrO}_{x}$ electrodes was then investigated by applying a $\mathrm{pH}$ sweep from high $\mathrm{pH}(\mathrm{pH} \approx 13.5)$ to low $\mathrm{pH}(\mathrm{pH} \approx 9.5)$ with the set-up described in section 2.4. Changes in the $\mathrm{pH}$ of the solution were performed either stepwise or continuously:

- $\quad$ Stepwise $\mathrm{pH}$ changes were achieved by exchanging the exposure solution (Table 2) or by adding given quantities of alkalinity or acidity. Between steps, the $\mathrm{pH}$ was kept constant (frequently monitored with a commercial glass $\mathrm{pH}$-electrode and corrected if needed). Steps in $\mathrm{pH}$ were made after exposure of at least 4 days to the same $\mathrm{pH}$ and once a potential drift lower than $0.5 \mathrm{mV} /$ day was reached.

- Gradual (slow) pH changes were achieved by leaving the solution exposed to air and allowing to react with $\mathrm{CO}_{2}$ from the atmosphere (natural carbonation). The $\mathrm{pH}$ of the solution over time was controlled with a commercial glass electrode

After these measurements, the electrodes were preserved in $\mathrm{pH} \approx 13.5$. For some $\mathrm{IrO}_{\mathrm{x}}$ electrodes, stepwise $\mathrm{pH}$ changes were applied 2-3 times, i.e. the $\mathrm{pH}$ was decreased from $\mathrm{pH} \approx 13.5$ to $\mathrm{pH} \approx 9.3$ and then brought back to $\mathrm{pH} \approx 13.5$, in order to study the reproducibility and reversibility of the potential response. The time difference between two consecutive measurements at a given $\mathrm{pH}$ was between 20 and 30 days. Afterwards, the $\mathrm{pH}$ of the solution was also kept constant at $\mathrm{pH} \approx 13.5$.

The $\mathrm{pH}$ exposure history will be indicated together with the results.

\subsubsection{Influence of conditioning on the potential-pH response}

With "conditioning" we mean the duration of the initial exposure of the electrodes to alkaline solutions, i.e. prior to being subjected to the procedure described in section 2.5.1 for measuring the $E-p H$ response. In order to study the influence of conditioning, the $\mathrm{IrO}_{x}$ electrodes of batch VIII were directly tested after being produced (without previous exposure to solution) during short time in solutions of different $\mathrm{pH}$ : the electrodes were initially immersed at $\mathrm{pH} \approx 13.5$ ("Borate 4", Table 2) for $<1 \mathrm{~min}$, and then they were washed and transferred to the next solution also for $<1 \mathrm{~min}$ and so on (following the sequence Borate $4 \rightarrow$ Borate $3 \rightarrow$ Borate $2 \rightarrow$ Borate 1 , Table 2 ). For all these measurements, the potential drift 
was always less than $2 \mathrm{mV} / \mathrm{min}$. After these measurements, the electrodes were preserved in $\mathrm{pH} \approx 13.5$ ("Borate 4", Table 2) and the procedure described in section 2.5 .1 was later applied.

This relatively fast protocol of measurements at different $\mathrm{pH}$ values was repeated with the electrodes of batch VIII after 8 and 23 days of immersion in "Borate 4" (pH 13.5 , Table 2).

\subsubsection{Oxygen dependency}

The aim of this experiment is to evaluate whether the potential response of the $\mathrm{IrO}_{x}$ electrodes is influenced by the oxygen concentration in solution. For this test, both an $\mathrm{IrO}_{x}$ electrode and a stainless steel bar were immersed in the test solutions (Table 2) according to the set-up described in section 2.4. When the potential of the $\mathrm{IrO}_{x}$ electrode and stainless steel stabilized (potential drift lower than $5 \mathrm{mV} / \mathrm{min}$ ), nitrogen was bubbled into the solution in order to remove the oxygen. A decrease in the potential of the stainless steel electrode was used as an indicator of the decrease in oxygen concentration [8] during nitrogen bubbling. The experiment lasted between 2 and 3 hours and it was performed for several $\mathrm{IrO}_{\mathrm{x}}$ electrodes immersed in the test solutions (Table 2).

\section{Results}

\subsection{Influence of fabrication protocol on electrode morphology}

Figure 3 shows representative examples of the SEM analysis of the cross sections of the produced $\mathrm{IrO}_{\mathrm{x}}$ electrodes obtained with the different cooling times and cleaning processes described in section 2.2. 


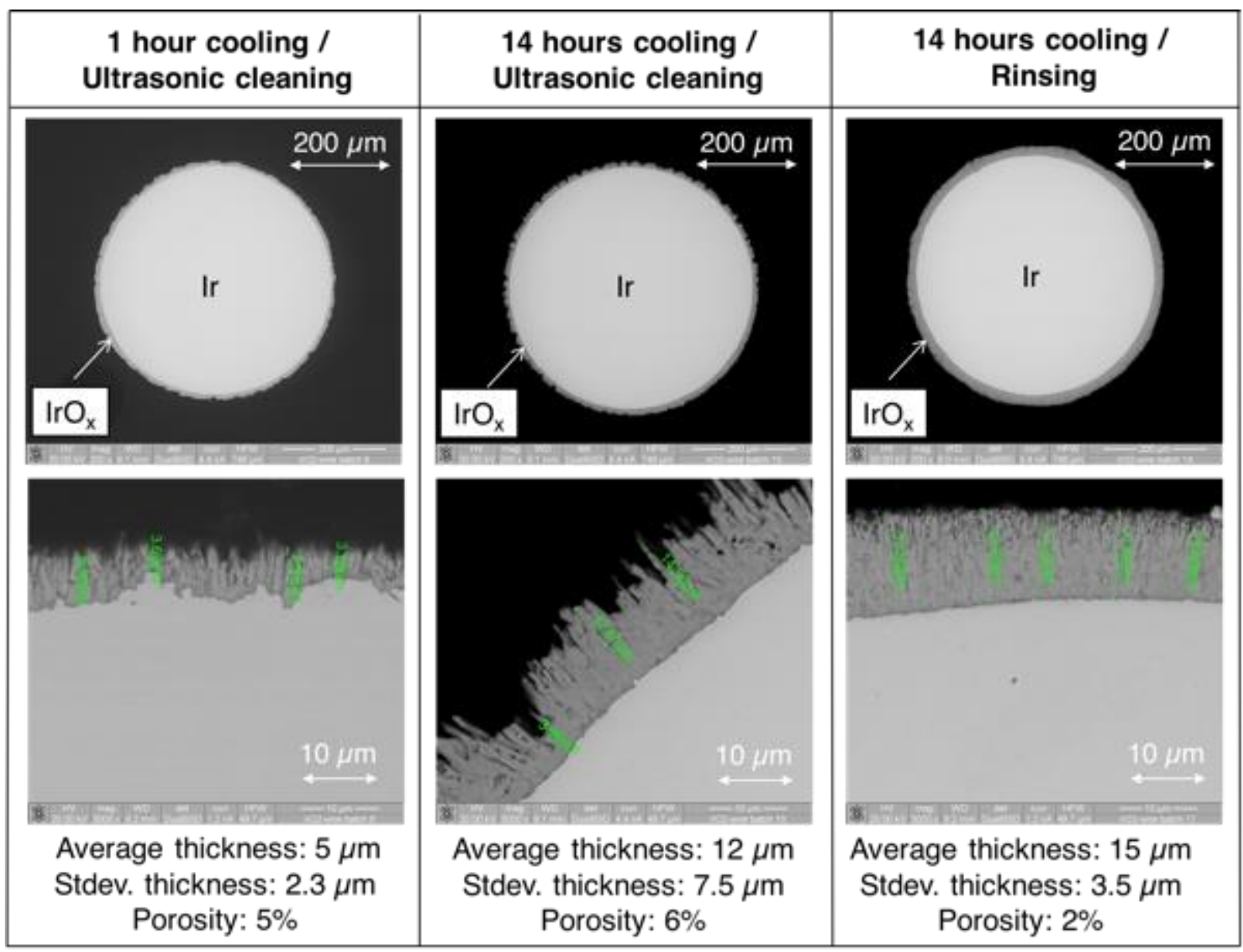

Fig. 3 SEM images of the cross section of $\mathrm{IrO}_{x}$ electrodes produced with different cooling times (1 hour and 14 hours) and cleaning processes (ultrasonic cleaning vs. rinsing). The average thickness (together with the standard deviation) and the porosity of the oxide layer are also provided for each $\mathrm{IrO}_{\mathrm{x}}$.

The $\mathrm{IrO}_{\mathrm{x}}$ electrodes formed by thermal oxidation generally exhibited a columnar structure with high aspect ratio grains, but there were significant differences in the oxide thickness and porosity depending on the cooling time and the type of cleaning performed (Fig. 3). Table 3 provides all data on thickness and porosity of the oxide layer for all the batches produced with different cooling and cleaning processes.

Table 3. Average thickness, standard deviation of the thickness, and porosity of the iridium oxide layer formed with different cooling and cleaning processes (ultrasonic cleaning vs. rinsing).

\begin{tabular}{ccccc}
\hline \multirow{2}{*}{ Cleaning process } & Cooling process & $\begin{array}{c}\text { Average } \\
\text { thickness }(\mu \mathrm{m})\end{array}$ & $\begin{array}{c}\text { Stdev. } \\
\text { thickness } \\
(\mu \mathrm{m})\end{array}$ & Porosity (\%) \\
\hline \multirow{3}{*}{ ultrasonic } & Fast (1 hour) & $5^{*}$ & 2.3 & 5 \\
\cline { 2 - 5 } & Slow (14 hours) & 7 & 2.5 & 7 \\
\cline { 3 - 5 } & & 20 & 6 & 7 \\
\hline
\end{tabular}




\begin{tabular}{ccccc}
\hline & & 11 & 4.2 & 6 \\
\hline \multirow{3}{*}{ rinsing } & Fast (1 hour) & 6 & 2 & 3 \\
\cline { 2 - 5 } & \multirow{2}{*}{ Slow (14 hours) } & 22 & 2.5 & 2.5 \\
\cline { 3 - 5 } & & $15^{*}$ & 3.5 & 2 \\
\hline
\end{tabular}

* shown in Figure 3

From the data in Table 3 it can be deduced that overall thicker oxide layers are obtained for the slow cooling process (14 hours). $\mathrm{IrO}_{x}$ electrodes with lower porosity and more homogeneous oxide layer thicknesses were obtained by rinsing with ultrapure water, avoiding ultrasonic cleaning. Optical microscopy also showed that after ultrasonic cleaning, part of the oxide was occasionally detached and iridium metal was exposed.

As a consequence of these results, only $\mathrm{IrO}_{\mathrm{x}}$ electrodes based on the slow cooling process (14 hours) with a careful posterior rinsing of the wires (no ultrasonic cleaning) were used for the electrochemical measurements presented in the following sections.

\subsection{Potential-pH response}

\subsubsection{Influence of conditioning on E-pH slope}

Figure 4 shows the average $E-p H$ response curves obtained directly after production (no conditioning) and after 8 and 23 days of conditioning in $\mathrm{pH} \approx 13.5$ of the electrodes produced in batch VIII. These results were obtained with the protocol described in section 2.5.2. The fitting coefficients for the potential-pH response curves shown in Fig. 4 are given in Table 4.

Table 4 Fitting coefficients, together with the standard deviation, for the $E-p H$ response curves (average of five individual IrOx electrodes) obtained with the protocol described in section 2.5.2 (for batch VIII, at different conditioning times in $\mathrm{pH} \approx 13.5$ ) shown in Fig. 4.

\begin{tabular}{ccccc}
\hline $\begin{array}{c}\text { Conditioning } \\
\text { time (days) }\end{array}$ & $\begin{array}{c}\text { Slope } \\
(\mathbf{V} / \mathbf{p H})\end{array}$ & $\begin{array}{c}\text { Stdev. slope } \\
(\mathbf{V} / \mathbf{p H})\end{array}$ & $\begin{array}{c}\text { Intercept (V vs. } \\
\mathbf{A g} / \mathbf{A g C l} / \mathbf{s a t . ~} \mathbf{K C l})\end{array}$ & $\begin{array}{c}\text { Stdev. intercept (V } \\
\text { vs. Ag/AgCl/sat. } \mathbf{~ K C l})\end{array}$ \\
\hline 0 & -0.031 & 0.007 & 0.503 & 0.068 \\
\hline 8 & -0.050 & 0.005 & 0.693 & 0.052 \\
\hline 23 & -0.052 & 0.003 & 0.723 & 0.042 \\
\hline
\end{tabular}




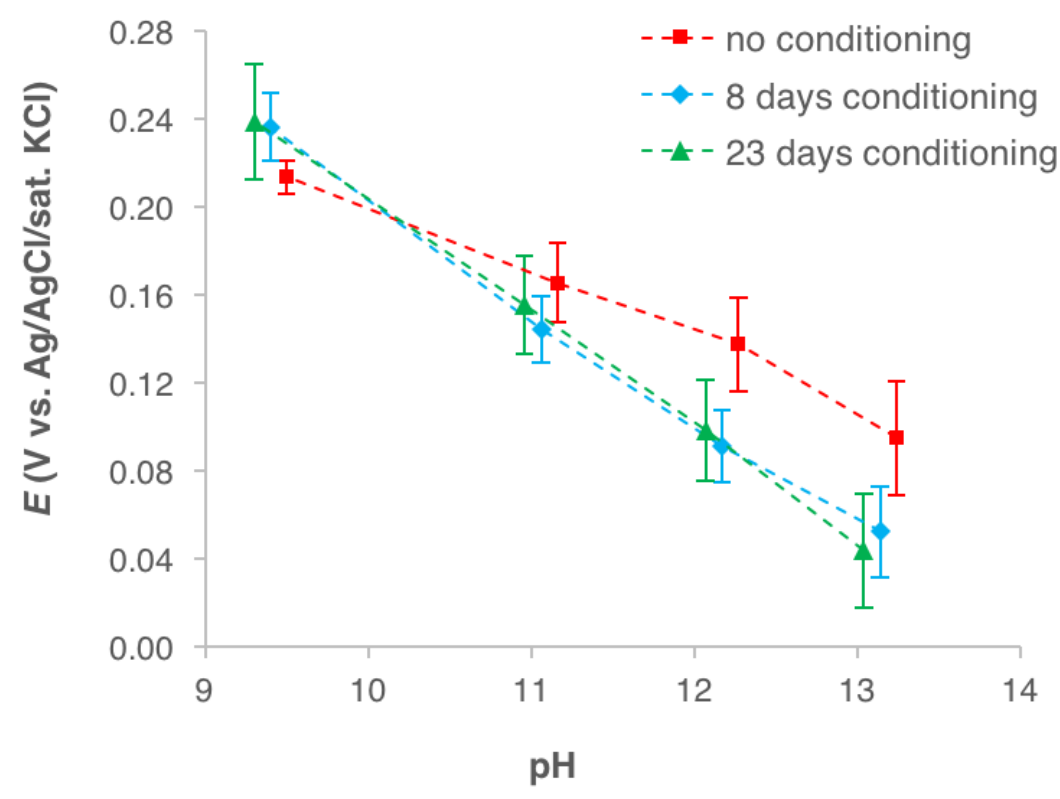

Fig. 4 Average and standard deviation of the potential $-\mathrm{pH}$ response of five individual $1 \mathrm{rO} \mathrm{O}_{\mathrm{x}}$ electrodes (produced in batch VIII) after different conditioning times in $\mathrm{pH} \approx 13.5$ (measurements at each $\mathrm{pH}$ exposure lasted $<1 \mathrm{~min}$, i.e., protocol described in section 2.5.2). The $\mathrm{pH}$ values from the curves "no conditioning" and "8 days conditioning" were slightly shifted in the graph for the sake of clarity.

It can be seen that the values of $E-p H$ slope and $E-p H$ intercept increase (in absolute value) with conditioning time. The results after 8 and 23 days of conditioning are similar.

\subsubsection{Influence of conditioning on response time}

The time from immersion, once the $\mathrm{pH}$ was changed, until the potential drift was $<2 \mathrm{mV} /$ day was considered the response time.

Fig. 5 shows the potential $\Delta E$ vs. time response of $\mathrm{IrO}_{\mathrm{x}}$ electrodes when exposed to a certain $\mathrm{pH}$ (here $\mathrm{pH}=13.5$ ). The potential difference $\Delta E$ is defined as the difference between $\operatorname{IrO}_{\mathrm{x}}$ response $E_{\text {lrox }}\left(\mathrm{t}=\mathrm{t}_{\text {response }}\right)$ when the potential changed $<2 \mathrm{mV} /$ day and the $\mathrm{IrO}_{\mathrm{x}}$ response $E_{\text {lrox }}$ $(\mathrm{t})$ at a given time.

$\Delta E(t)=E_{\operatorname{IrO}_{\mathrm{x}}}\left(t=t_{\text {response }}\right)-E_{\operatorname{IrO}_{\mathrm{x}}}(t)$

In Fig. 5, two different cases are shown (no pre-conditioning vs. conditioning for a certain time, indicated in the graph). For each scenario, two representative examples of $\mathrm{IrO}_{\mathrm{x}}$ electrodes were selected ( $\mathrm{IrO}_{x} 9$ form batch VII and $\mathrm{IrO}_{x} 4$ from batch VIII). For the two electrodes that were not pre-conditioned, the response time was approximately one month. In contrast, for the two electrodes that were conditioned in alkaline solutions for 76 and 152 days, respectively, the response time became much shorter, namely in the order of days. The same trend was observed for the other produced $\mathrm{IrO}_{\mathrm{x}}$ electrodes. 


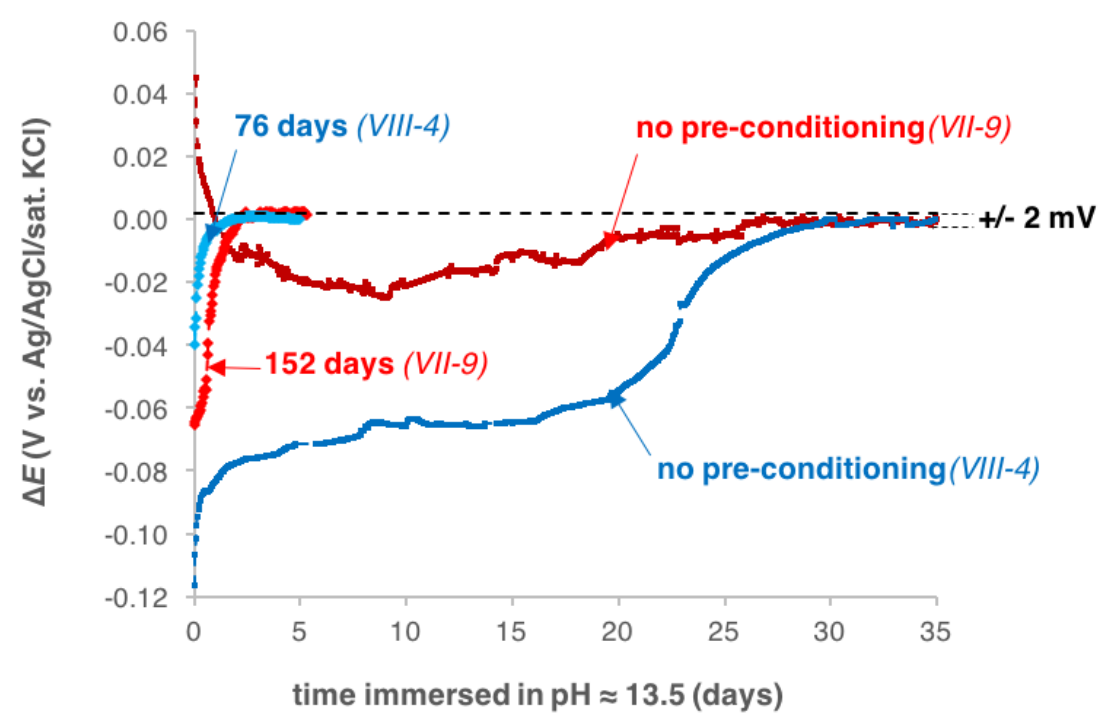

Fig. 5 Potential difference $\Delta E$ (equation (2)) as a function of the immersion time in $\mathrm{pH} \approx 13.5$ for different conditioning times in alkaline solution (indicated in the graph) of two $\mathrm{IrO}_{x}$ electrodes $\left(\mathrm{IrO}_{x} 9\right.$ from Batch VII and IrO 4 from batch VIII); response time $=$ time to reaching a potential drift $<2$ $\mathrm{mV} /$ day) The potential change over time ( $2 \mathrm{mV} /$ day) accepted is also indicated in the graph.

\subsubsection{Potential-pH response - after conditioning}

This section presents the $E-p H$ response of the $\mathrm{IrO}_{x}$ electrodes, determined after sufficient conditioning (protocol described in section 2.5.1). Figure 6 shows the average of potential responses of the $\mathrm{IrO}_{x}$ electrodes produced in each batch as a function of the $\mathrm{pH}$ of the solution. For each batch, the linear fit for the relationship between potential and $\mathrm{pH}$ is also plotted, together with the theoretical E-pH response according to Pourbaix [29]. The fitting coefficients of the $E-p H$ curves of each individual IrO ${ }_{x}$ electrodes (38 in total), together with the information regarding the $\mathrm{pH}$-range exposure history is provided in Table $\mathrm{S} 1$ (Supplementary Material).

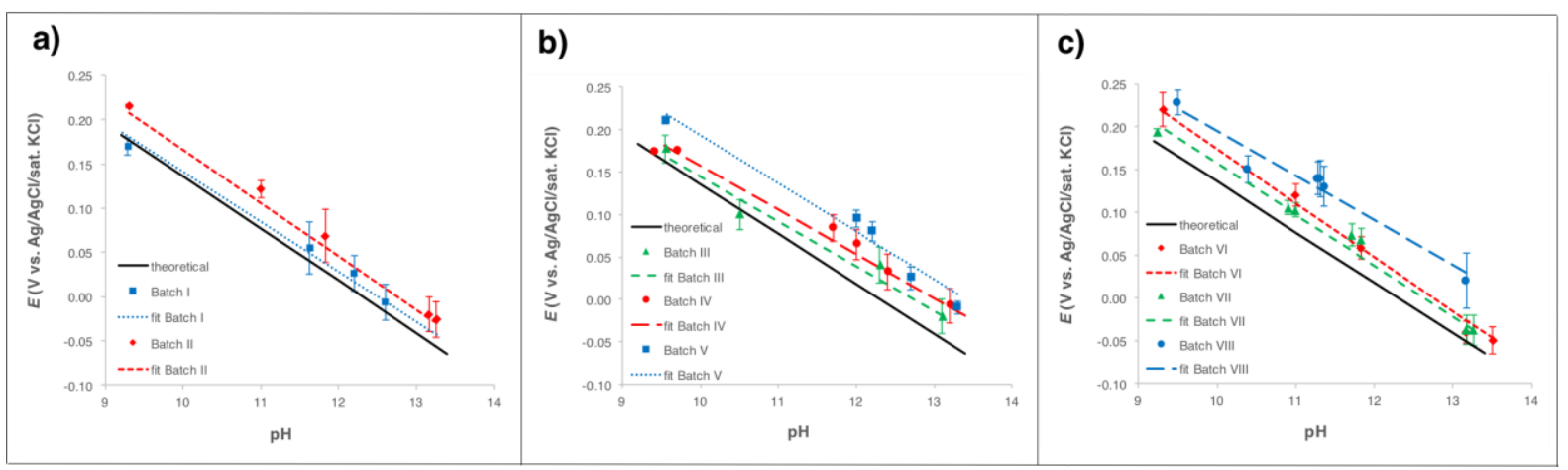

Fig. 6 Average of potential responses of the IrOx electrodes of batches: I and II (a) III-V (b) VI-VIII (c). Immersion time at each $\mathrm{pH}$ lasted at least 4 days. For each batch, the linear fit for the $E-p H$ relationship is given (differentiated by line and color), together with the standard deviation (error bars) of the individual readings (of 3-9 individual $\mathrm{IrO}_{x}$ electrodes). The theoretical $E-p H$ response according to Pourbaix is also plotted [29]. 
Fig. 6 shows that the potential-pH slopes of the $\mathrm{IrO}_{\mathrm{x}}$ electrodes are generally in good agreement with the theoretical potential-pH response according to Pourbaix [29]. The E-pH slopes of individual electrodes are between $-0.050 \mathrm{~V} / \mathrm{pH}$ and $-0.068 \mathrm{~V} / \mathrm{pH}$ and the standard deviation is between 0.002 and $0.007 \mathrm{~V} / \mathrm{pH}$ (Table S1).

The E-pHintercepts of individual electrodes are between 0.605 and $0.863 \mathrm{~V}$ vs. $\mathrm{Ag} / \mathrm{AgCl} / \mathrm{sat}$. $\mathrm{KCl}$ and the standard deviation is between 0.019 and $0.075 \mathrm{~V}$ vs. $\mathrm{Ag} / \mathrm{AgCl} / \mathrm{sat}$. $\mathrm{KCl}$ (Table S1). Interestingly, almost all measured potentials were more positive than the values suggested by Pourbaix [29].

Note that the electrodes produced in batches I-V had different exposure histories within the range of $\mathrm{pH}$ between 9.3 and 13.5 over more than one year. Nevertheless, their $E-p H$ response curve is in agreement with the rest of the results.

\subsubsection{Reproducibility and reversibility}

For several individual $\mathrm{IrO}_{\mathrm{x}}$ electrodes, the protocol described in 2.5.1 (stepwise $\mathrm{pH}$ changes) was repeated 2-3 times to study the reproducibility of the $E-p H$ response of a single electrode (once they were sufficiently conditioned). A representative example of three $E-p H$ response curves repeatedly obtained for the same electrode (electrode 1 , batch I) is shown in Figure 7. The order of the measurements is also indicated in the graph. The complete set of results (for $29 \mathrm{IrO}_{x}$ out of the 38 produced) is provided in Table S2 (Supplementary Material).

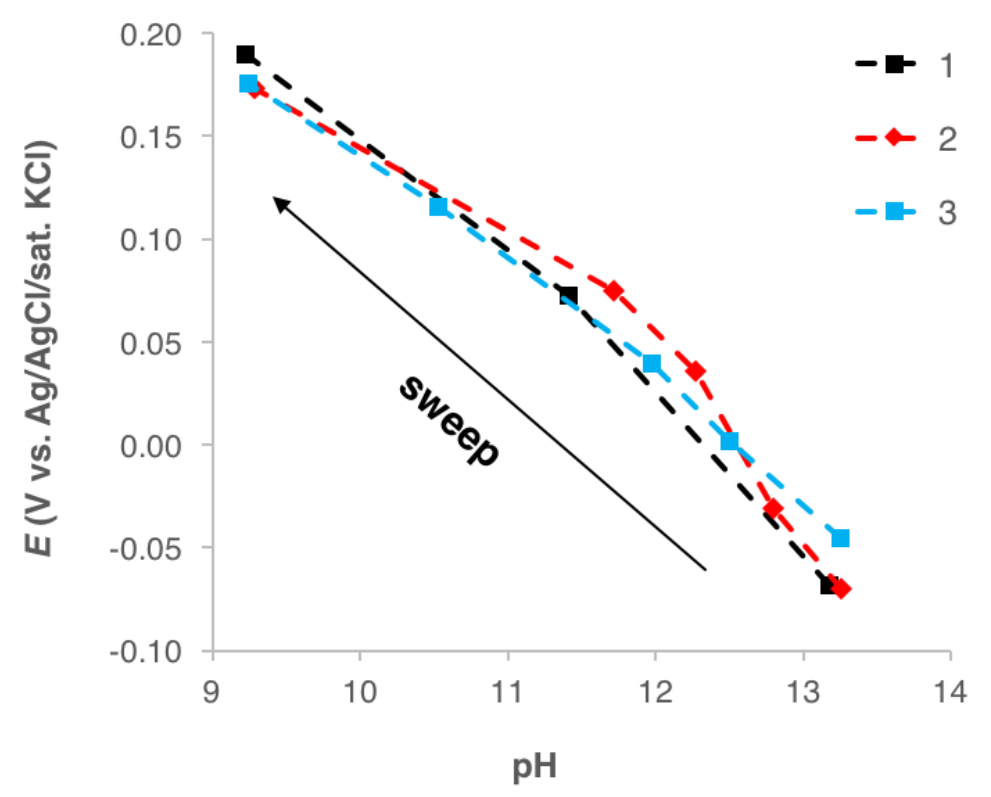

Fig. 7 Reproducibility of the $E-p H$ response of sufficiently conditioned electrodes (representative example; electrode1, batch I). Each time, the electrode was first exposed to $\mathrm{pH} 13.5$ and then the $\mathrm{pH}$ 
was stepwise decreased to 9.3 . A pH sweep from 13.5 to 9.3 took 20-30 days. The numbers indicated in the graph $(1,2,3)$ refer to the order in which the measurements were performed.

From Fig. 7, it can be noted that the potential response can be considered reversible and reproducible; only small differences between the different curves can be observed. The same behaviour was found for the rest of electrodes produced (Table S2 in the Supplementary Material). The maximum difference between potential readings for the same electrode measured at the same $\mathrm{pH}$, but at different periods in time was typically in the range of $20 \mathrm{mV}$. Concerning the potentiometric determination of the $\mathrm{pH}$, this would correspond to an error of maximum $0.5 \mathrm{pH}$ units for pre-calibrated $\mathrm{IrO}_{x}$ electrodes.

\subsubsection{Oxygen dependency}

A representative example of the potential of the $\mathrm{IrO}_{x}$ electrode and the stainless steel immersed in solution of $\mathrm{pH} 13$ is shown in Fig. 8. The same trend was observed for the other produced $\mathrm{IrO}_{\mathrm{x}}$ electrodes immersed in the other test solutions (Table 2).

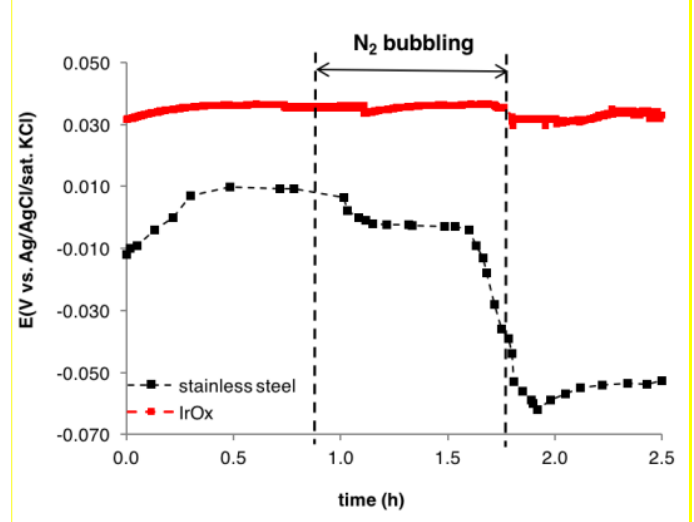

Fig. 8 Potential of a produced IrOx (IrOx 1 from Batch III) and stainless steel bar immersed in $\mathrm{pH} \approx 13$ as a function of time while oxygen content is decreased due to nitrogen bubbling into the solution (indicted in the graph).

From Fig. 8, it can be seen that while nitrogen was bubbled into the test solution, the potential of steel significantly decreased while the potential of the $\mathrm{IrO}_{x}$ electrode remained essentially unaffected (maximum changes within a few millivolts). It thus becomes apparent that the oxygen concentration in solution does not affect the potential of the $\mathrm{IrO}_{\mathrm{x}}$ electrodes produced in this study, which is in agreement with other works $(12,29)$.

\subsection{Long-term stability}

For engineering applications, long-term stability is the most important property for the $\mathrm{IrO}_{x}$ electrodes. Figure $9 \mathrm{a}$ shows the potential response of an $\mathrm{IrO}_{\mathrm{x}}$ (electrode 1, batch II) as a 
function of time while undergoing a exposure history to varying $\mathrm{pH}$ for 1.5 years. Fig. 9b, shows the magnified area of the graph when the $\mathrm{pH}$ of the solution was kept constant at $\mathrm{pH}$ $\approx 13.5$ after 540 days of exposure.

a)

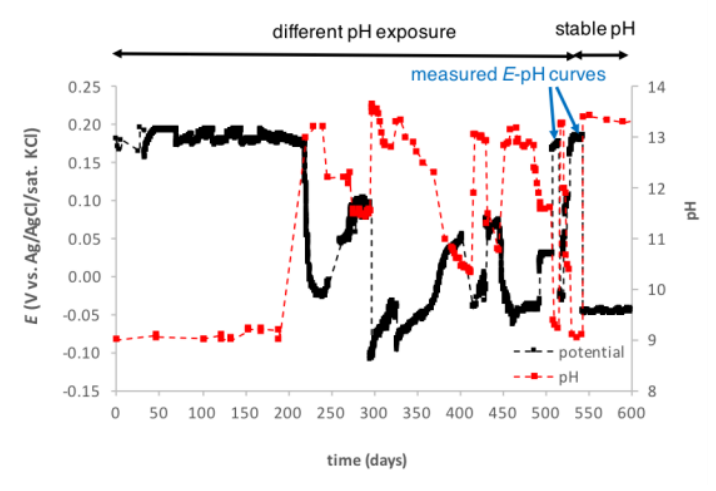

b)

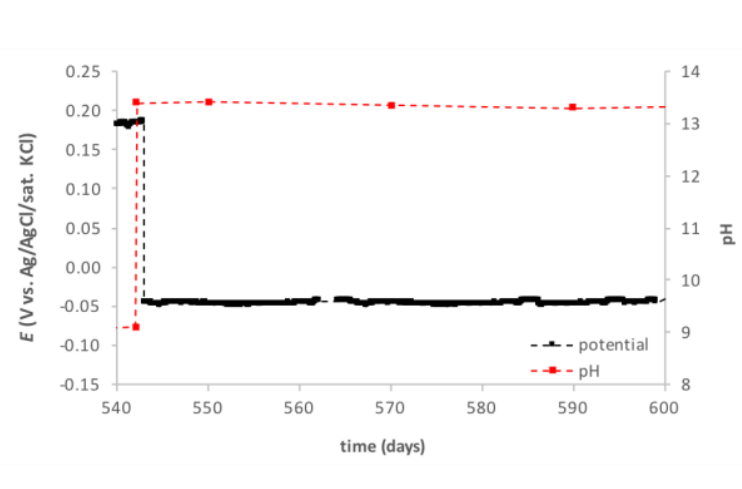

Fig. 9 (a) Potential response of an $\mathrm{IrO}_{x}$ (electrode 1, batch II) as a function of time while undergoing a history of variable $\mathrm{pH}$ exposure (b) Magnified area of the graph after 540 days of immersion and when the $\mathrm{pH}$ is kept constant at 13.5 .

Several aspects in the results presented in Figure 9 deserve attention. First of all, this $\mathrm{IrO}_{x}$ was subjected to a history of variable $\mathrm{pH}$ for more than one year before the $E-p H$ curves were obtained (Fig. 9a). Nevertheless, the potential-pH response curves measured are in agreement with the rest of results (see Table S1 and Table S2 in the Supplementary Material).

Secondly, it can be observed that as long as the $\mathrm{pH}$ was kept constant, the potential response varied less than $+/-2 \mathrm{mV}$ over 80 days, thus without potential drift. In addition, the response time was very short (ca. 1 day) when the $\mathrm{pH}$ was increased from 9.3 to 13.5 after 540 days of immersion in alkaline solution (Fig. 9b), in agreement with the results presented in section 3.1.2.

The same behaviour was observed for the rest of the electrodes immersed in the different solutions, always after "sufficient" conditioning time (see section 4.2). Table S3 in the Supplementary Material reports the total immersion time in alkaline solution, the immersion time in $\mathrm{pH} \approx 13.5$ when the potential drift was $<0.5 \mathrm{mV} /$ day, and the potential response in $\mathrm{pH} \approx 13.5$ (when the potential drift was $<0.5 \mathrm{mV} /$ day).

\section{Discussion}

\subsection{Potential-pH response}

It was observed that each produced $\mathrm{IrO}_{\mathrm{x}}$ electrode responds slightly different (section 3.2.3) and that its response is also influenced by the conditioning time (sections 3.2.1 and 4.2). It is 
thus recommended that previous conditioning and pre-calibration of each $\mathrm{IrO}_{\mathrm{x}}$ electrode is performed before use. Given the variability within all electrodes, this will enhance the accuracy of the measurements of the single electrode compared to simply using general (average) slope and standard potential.

- Slope: The range of $E-p H$ slopes values obtained, after sufficient conditioning, was between $-0.050 \mathrm{~V} / \mathrm{pH}$ and $-0.068 \mathrm{~V} / \mathrm{pH}$ (table S1, Fig. 6), i.e. relatively close to the $0.059 \mathrm{~V} / \mathrm{pH}$ slope reported for $\mathrm{IrO}_{\mathrm{x}}$ electrodes produced by thermal oxidation $[17,19,20]$ and in agreement with Pourbaix [29]. It is believed that the differences in slope obtained in this study with respect to the reported $-0.059 \mathrm{~V} / \mathrm{pH}$ may be due to the porosity of the exposed oxide layer, which may influence ion exchange $[15,30]$. It should be also noted that the total immersion time of the electrodes in this work is much longer (months - years) than in other studies (generally minutes to days, see Table 1). Different immersion times, i.e., conditioning times (section 4.2), could also explain the reported differences in $\mathrm{pH}$-slopes in literature $[1,12-16,22]$.

- Standard potential: $\mid \mathrm{IO}_{\mathrm{x}}$ electrodes formed by thermal oxidation have been reported to be $($ semi)-anhydrous $[17,19,20]$ with intercept values of the $E-p H$ relationship similar to the value according to Pourbaix [29], i.e., $0.736 \mathrm{~V}$ vs. $\mathrm{Ag} / \mathrm{AgCl} / \mathrm{sat}$. $\mathrm{KCl}$. In this work, the average value is close to theory ( $0.733 \mathrm{~V}$ vs. $\mathrm{Ag} / \mathrm{AgCl} / \mathrm{sat}$. $\mathrm{KCl})$ but the variability among the intercept values obtained is high (average $0.733 \mathrm{~V}$ with scatter between 0.605 and $0.863 \mathrm{~V}$ vs. $\mathrm{Ag} / \mathrm{AgCl} / \mathrm{sat}$. $\mathrm{KCl}$ (Tables S1 and S2 in the Supplementary Material)). From Fig. 6 it can be seen that the potential responses of many electrodes at a given $\mathrm{pH}$ are higher than the theoretical curve for $\operatorname{lr}_{2} \mathrm{O}_{3} \cdot \mathrm{nH}_{2} \mathrm{O}$ / $\mathrm{IrO}_{2} \mathrm{nH}_{2} \mathrm{O}$ (theoretical potential-pH response according to Pourbaix [29]); this could be explained by the presence of other (hydrated) iridium oxides other than the $\mathrm{Ir}_{2} \mathrm{O}_{3} \cdot \mathrm{nH}_{2} \mathrm{O} / \mathrm{IrO}_{2} \mathrm{nH}_{2} \mathrm{O}$ couple [31]. For example, Wang et al. [19], reported that the electrode produced with a method similar to the present one was $\mathrm{Li}_{0.86}$ $\mathrm{IrO}_{2.34}(\mathrm{OH})_{0.76} \cdot 0.39 \mathrm{H}_{2} \mathrm{O}$. However, the electrodes produced in this case were stored in neutral solution $\left(4 \mathrm{KCl} \mathrm{mol} \cdot \mathrm{L}^{-1}\right)$ or in air between the measurements. Therefore, the hydration state of the present electrodes is likely different, since they had been continuously immersed in alkaline solution. 


\subsection{Influence of conditioning}

\subsubsection{Influence of conditioning on potential-pH response}

According to the present results, the total immersion time in alkaline solution (conditioning time) plays an important role in obtaining a reproducible and stable potential reading upon exposure to a certain $\mathrm{pH}$ (section 3.2.1).

The values of $E-p H$ slope and $E-p H$ intercept change with conditioning time. When not properly conditioned, the potential response of the studied electrodes changes over time (Fig. 4), but after "sufficient" conditioning time, the individual $\mathrm{IrO}_{\mathrm{x}}$ electrodes exhibit a reproducible potential response, regardless of the previous exposure (section 3.2.4). Figure S2 in the Supplementary Material gives the average total immersion time in alkaline solution until obtaining reproducible potential response when immersed in $\mathrm{pH} \approx 13.5$, differentiated by batch. The data in Figure $\mathrm{S} 2$ show that in order to obtain a reproducible response, sufficient conditioning time is needed. For some electrodes, this may be the case already after 50 days, while for others, it may take up to 250 days.

In section 4.1 , it was suggested that the oxide layer formed is probably composed by oxide forms other than the $\mathrm{Ir}_{2} \mathrm{O}_{3} \cdot \mathrm{nH}_{2} \mathrm{O} / \mathrm{IrO}_{2} \mathrm{nH}_{2} \mathrm{O}$; most likely hydrated as the studied $\mathrm{IrO}$ in this study are continuously immersed in alkaline solution [1,12-16,22]. It is believed that the time needed until obtaining a reproducible potential response at a given $\mathrm{pH}$ is due to the "hydration" of the oxide layer formed. Trasatti [32] suggested that the "wetting" of dry oxide films may take more than 2 months.

\subsubsection{Influence of conditioning and morphology on response time}

The $\mathrm{IrO}_{\mathrm{x}}$ electrodes formed by thermal oxidation exhibit a columnar structure with high aspect ratio grains, as previously observed in other studies $[17,19,20]$. Table 3 shows that overall thicker oxide layers were obtained for the longer cooling time in the production protocol. This may be explained by increased oxidation times when slower cooling was permitted [26,27].

The thickness of the oxide layer does not seem to influence the response time (Figure S1 in the Supplementary material). Nevertheless, we consider thicker oxide layers as beneficial for the application for long-term $\mathrm{pH}$ monitoring because higher thickness increases the robustness of the electrodes.

In section 3.1 it was shown that the oxide layers can exhibit some very narrow pores (Fig. 3 and Table 3); this could explain why response times in the order of days were obtained in some cases (Fig. 5), as increased porosity may be translated into longer response times $[15,30]$. Nevertheless, the results presented in Fig. 5 show that the response time strongly 
decreases when the electrodes were immersed in alkaline solution for a certain conditioning time.

Fig. 10 shows the response time (see section 3.1.2) as a function of the porosity of the oxide layer, differentiated by electrodes conditioning.

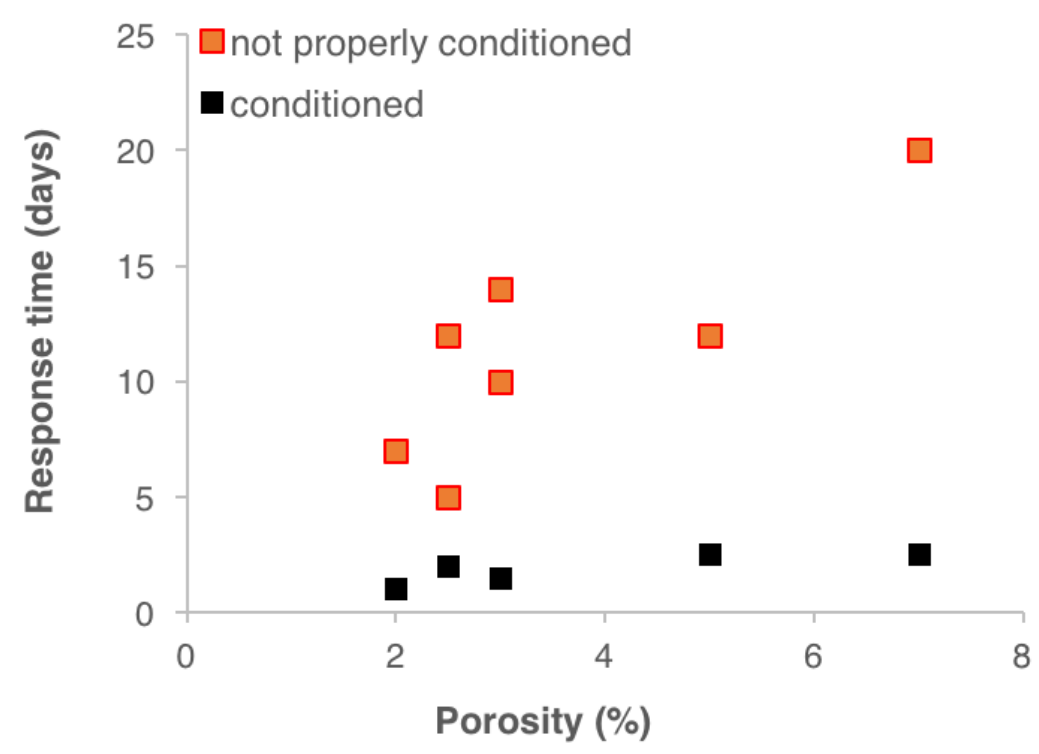

Fig. 10 Response time as a function of the porosity of the oxide layer, differentiated by electrodes with sufficient / insufficient conditioning time (response time $=$ time to reaching a potential $\mathrm{drift}<2 \mathrm{mV}$ during 1 day)

The response time of the electrodes strongly decreases if they were conditioned for a sufficient time. Furthermore, the response time increases with the porosity for the electrodes that were not properly conditioned.

\subsubsection{Sufficient conditioning}

In conclusion, it appears that the produced iridium oxide electrodes need to be conditioned in alkaline solution in order to provide both a reproducible potential-pH response and relatively short response time. Based on the current results, we suggest that the electrodes need 3-4 months of immersion in alkaline solution until they provide fully reproducible potentials at a given $\mathrm{pH}$.

\section{Application in research and engineering}

\subsection{Concrete structures}

Corrosion of steel reinforcement is the most frequent cause of failure in reinforced concrete structures [33]. The $\mathrm{pH}$ of the concrete pore liquid and solid alkaline components such as 
$\mathrm{Ca}(\mathrm{OH})_{2}$ play a major role in the ability of reinforced concrete to withstand corrosion - both for carbonation-induced and for chloride-induced corrosion [8].

Common methods to determine the $\mathrm{pH}$ in concrete used in science and engineering of concrete durability are destructive and can thus not provide continuous information at a certain location $[34,35]$. The most established method in practice is based on spraying an indicator solution on a freshly exposed concrete surface [35]. Only a few indicator solutions have proven applicable to concrete, the most common ones are phenolphthalein (changing color between $\mathrm{pH} 8$ and 9) or thymolphthalein (changing color between $\mathrm{pH} 9$ and 10). This approach for $\mathrm{pH}$ measurements basically provides a yes/no answer and gives no information about the $\mathrm{pH}$ changes above and below the characteristic $\mathrm{pH}$ at which the used indicator solution changes color. The accuracy is roughly one $\mathrm{pH}$ unit. Other approaches to determine the $\mathrm{pH}$ of concrete are based on crushing concrete samples and exposing them to a leaching agent [34]. While this may yield more finely graded results than the indicator spray test, the methods are laborious and time-consuming. Additionally, leaching methods do not permit measuring the $\mathrm{pH}$ in the concrete at moisture states below saturation.

In contrast to these approaches, the $\mathrm{IrO}_{\mathrm{x}}$ electrodes used as $\mathrm{pH}$ sensors presented in this work provide relatively highly resolved $\mathrm{pH}$ measurements. As the method is non-destructive, embedded electrodes allow measurements over time (with a high time resolution) for given locations in the concrete, which is not possible with destructive measurements. These are considered important advantages for various applications.

One example is all research aiming at studying the penetration of the carbonation front through the concrete cover. If embedded at certain depths, the $\mathrm{IrO}_{\mathrm{x}}$ electrodes can provide detailed insight in the kinetics of the carbonation and the time evolution of the solution $\mathrm{pH}$, which is, depending on the type and amounts of solid phases, buffered at different pH levels. It may be particularly interesting to study non-Portlandite binders that likely exhibit very different shapes in evolution of $\mathrm{pH}$ vs. time [36-38]. Additionally, the $\mathrm{IrO}_{\mathrm{x}}$ electrodes permit measuring the $\mathrm{pH}$ in the concrete at the exposure conditions favorable for carbonation, which are below saturation state [39].

These electrodes may in principle be applied also in monitoring of engineering structures, i.e. embedded in the concrete cover zone at different depths. This would permit measuring the $\mathrm{pH}$ as a function of time and cover depth. On this basis, the time until the $\mathrm{pH}$ becomes depressed to a certain value at the steel surface could be extrapolated and allow for a prediction of the time to depassivation. 
Another possible application of the sensors could be the validation of the existing carbonation models [40-42]. These models are typically calibrated against experimental data determined with the indicator solution spray test. In this regard, detailed knowledge of the $\mathrm{pH}$ as a function of both time and cover depth permits refining and validating carbonation models for different exposure conditions and for different binders.

In order to study the previously mentioned applications, the performance of the studied $\mathrm{IrO} \mathrm{X}_{\mathrm{x}}$ electrodes when embedded in concrete is currently under investigation. The experiments are based on embedding the electrodes at different depths in mortar and exposing them to onedimensional carbonation by placing the sample in a carbonation chamber $\left(65 \% \mathrm{RH}, 21^{\circ} \mathrm{C}\right.$ and $4 \% \mathrm{CO}_{2}$ ) while the potential response of the $\mathrm{pH}$ sensor is recorded. Preliminary results show that the electrodes can be used to monitor changes $\mathrm{pH}$ in-situ in the concrete pore solution of reinforced concrete [39]. Table 5 gives the potential response of an $\mathrm{IrO}_{\mathrm{x}}$ electrode ( $\mathrm{IrO}_{\mathrm{x}} 4$ produced in Batch $\mathrm{VI}$ ) embedded in mortar (at a cover depth $=15 \mathrm{~mm}$ ), before and after the sample was carbonated, together with the days of exposure to carbonation [39]. In this case, the $\mathrm{pH}$ was obtained from the average of the $E$ - $p H$ response curves (reported in this work, see Table S2) obtained for the corresponding $\mathrm{IrO}_{x}$ electrode.

Table 5 Potential response of an IrOx electrode (IrOx 4 produced in Batch VI) embedded in mortar (at cover depth $=15 \mathrm{~mm}$ ), before and after the sample was carbonated, together with the days of exposure to carbonation [39]. The $\mathrm{pH}$ was obtained from the average of the $\mathrm{E}-\mathrm{pH}$ response curves obtained for the corresponding IrOx electrode

\begin{tabular}{ccc}
\cline { 2 - 3 } & \multicolumn{2}{c}{ IrO embedded in mortar } \\
\hline pH & $\begin{array}{c}\text { Days in the } \\
\text { carbonation chamber }\end{array}$ & $\begin{array}{c}E(\mathrm{~V} \text { vs. } \\
\mathrm{Ag} / \mathbf{A g C l} / \mathbf{s a t} . \mathrm{KCl})\end{array}$ \\
\hline 13.2 & 5 & -0.022 \\
\hline 9.7 & 160 & 0.170 \\
\hline
\end{tabular}

From Table 5, it can be seen that the $\mathrm{pH}$ of uncarbonated concrete is ca. $\mathrm{pH} \approx 13$, while it decreases down to ca. $\mathrm{pH} \approx 10$ when it is carbonated, in agreement with literature [8]. Carbonation after 5 months at this depth was validated with the phenolphthalein spraying method. It is also interesting to note that even after more than 5 months of exposure to $\mathrm{CO}_{2}$ ingress and under relatively dry environment $(65 \% \mathrm{RH})$, the electrode functionality is still given [39]. The application of the studied $\mathrm{IrO}_{\mathrm{x}}$ in concrete thus seems to be a promising solution and more research is needed in this direction. 
In chloride-induced corrosion, the $\mathrm{pH}$ is known to play a major role $[9,43]$. Being able to measure the $\mathrm{pH}$ at the steel depth at the time of corrosion initiation would provide valuable information in addition to the chloride concentration, which is typically determined.

Finally, we would like to note that concrete is typically exposed to different exposure conditions, e.g. seasonal changes, that may lead to marked variations in the moisture content in the concrete. It has been indicated in this study that produced electrodes consist of a dense hydrated oxide layer. The effect of variable humidity needs to be studied in detail.

\subsection{Cathodic protection in soil}

In laboratory studies, it has been shown that relatively low protection current densities lead to a significant increase in $\mathrm{pH}$ at the steel surface [44]. Only a few $\mathrm{mA} / \mathrm{m} 2$ appear to be sufficient to raise the $\mathrm{pH}$ at the steel surface to values above 10 and provide effective cathodic protection.

However, determining the $\mathrm{pH}$ at the very surface of steel embedded in soil is difficult, mainly because of the pronounced change in $\mathrm{pH}$ with increasing distance from the metal surface. The solution (soil) volume relevant in the measurement is thus extremely small, which limits the use of commercial pH sensors that typically are too large. As a result, researchers either use highly specialized test set-ups, which may be limited in terms of being representative for practice, or rely on indirect measurements to estimate the $\mathrm{pH}$. To validate the existing literature data and to broaden knowledge (e.g. studying different soil types, chemical composition of the soil solution, and other experimental conditions) a more simple and direct method is thus desirable.

In this regard, the $\mathrm{IrO}_{\mathrm{x}}$ electrodes studied in this work are feasible. They are small, work well in the relevant range of $\mathrm{pH}(>9)$, and have response times that are sufficiently fast for the application in CP studies in soil. Considering the long-standing controversy about CP criteria based on potentials [44], being able to measure the $\mathrm{pH}$ in-situ in the soil would contribute to resolving open questions in research and practice.

\section{Conclusions}

Based on the major conclusions below, we consider the studied $\mathrm{IrO}_{x}$ electrodes feasible for long-term continuous monitoring purposes in corrosion engineering in concrete or soil. When properly produced, conditioned, and pre-calibrated, they permit measuring the $\mathrm{pH}$ with a maximum error of $0.5 \mathrm{pH}$ units in a range of at least $\mathrm{pH} 9$ to 13.5 .

The main findings obtained in this work are: 
- Conditioning: In order to provide accurate and reproducible potential-pH responses, the produced $\mathrm{IrO}_{\mathrm{x}}$ electrodes need conditioning in highly alkaline solutions for at least 3-4 months.

- Response time: Given sufficient conditioning, the response time of the electrodes varied between a few hours to a few days. This is sufficiently fast for monitoring $\mathrm{pH}$ changes in concrete or soil.

- Oxygen dependency: the potential exhibited by the produced iridium oxide electrodes seems to be independent on the oxygen concentration dissolved in the solution.

- Long-term stability: after immersion in different alkaline solutions for up to almost 2 years, the electrodes were still capable of responding reliably to $\mathrm{pH}$ changes. The oxide layers formed with the suggested procedure were relatively thick $(10-25 \mu \mathrm{m})$; we consider this beneficial for the long-term stability in concrete or soil.

- Response in concrete: preliminary results show that the studied electrodes permit monitoring $\mathrm{pH}$ changes when embedded in concrete.

\section{Acknowledgements}

The financial support from the Swiss National Science Foundation (SNF) is kindly acknowledged.

\section{References}

1. F. Contu, M. Vega-Arroyo, R. Taylor (2014) The fabrication and calibration of an iridium pH micro-sensor for biological applications. Int J Mat Sci 4 (1):8.

doi:10.14355/ijmsci.2014.0401.02

2. Pikulski M, Gorski W (2000) Iridium-based electrocatalytic systems for the determination of insulin. Anal Chem 72:2696-2702. doi:10.1021/ac000343f

3. Kreider K (1991) Iridium oxide thin-film stability in high-temperature corrosive solutions. Sens Actuators, B 5:165-169. doi:10.1016/0925-4005(91)80239-G

4. Bezbaruah AN, Zhang TC (2002) Fabrication of anodically electrodeposited iridium oxide film $\mathrm{pH}$ microelectrodes for microenvironmental studies. Anal Chem 74:5726-5733.

doi:10.1021/ac020326I

5. Ges IA, Ivanov BL, Schaffer DK, Lima EA, Werdich AA, Baudenbacher FJ (2005) Thinfilm IrOx pH microelectrode for microfluidic-based microsystems. Biosens Bioelectron 21

(2):248-256. doi:10.1016/j.bios.2004.09.021

6. Marzouk SAM, Ufer S, Buck RP, Johnson TA, Dunlap LA, Cascio WE (1998)

Electrodeposited iridium oxide $\mathrm{pH}$ electrode for measurement of extracellular myocardial acidosis during acute ischemia. Anal Chem 70 (23):5054-5061. doi:10.1021/Ac980608e 
7. Vonau W, Guth U (2006) pH Monitoring: a review. J Solid State Electrochem 10 (9): 746752. doi:10.1007/s10008-006-0120-4

8. Elsener B, Bertolini L, Pedeferri P, Polder RP (2013) Corrosion of steel in concrete. second edn. Willey, Weinheim

9. Hausmann DA (1967) Corrosion of steel in concrete. How does it occur? J Mater Prot 6:19-23

10. Behnood A, Tittelboom KV, Belie ND (2016) Methods for measuring pH in concrete: A review. Constr Build Mater 105:176-188. doi:10.1016/j.conbuildmat.2015.12.032 11. Du R-G, Hu R-G, Huang R-S, Lin C-J (2006) In situ measurement of $\mathrm{Cl}^{-}$concentrations and $\mathrm{pH}$ at the reinforcing steel: concrete interface by combination sensors. Anal Chem 78:3179-3185. doi:10.1021/ac0517139

12. Elsen HA, Monson CF, Majda M (2009) Effects of electrodeposition conditions and protocol on the properties of iridium oxide $\mathrm{pH}$ sensor electrodes. J Electrochem Soc 156 (1):F1-F6. doi:10.1149/1.3001924

13. Terashima C, Rao TN, Sarada BV, Spataru N, Fujishima A (2003) Electrodeposition of hydrous iridium oxide on conductive diamond electrodes for catalytic sensor applications. $J$ Electroanal Chem 544:65-74. doi:10.1016/s0022-0728(03)00066-4

14. Olthuis W, Robben MAM, Bergveld P, Bos M, Linden WEVd (1990) pH sensor properties of electrochemically grown iridium oxide. Sens Actuators, B 2:247-256. doi:10.1016/09254005(90)80150-X

15. Huang W-D, Cao H, Deb S, Chiao M, Chiao JC (2011) A flexible pH sensor based on the iridium oxide sensing film. Sens Actuators, A 169 (1):1-11. doi:10.1016/j.sna.2011.05.016 16. Huang W-D, Wang J, Ativanichayaphong T, Chiao M, Chiao JC Development of an IrOx micro pH sensor array on flexible polymer substrate. In: SPIE Nanosensors and Microsensors for Bio-Systems Conference California, 2008. p 693104. doi:10.1117/12.775856

17. Yao S, Wang M, Madou M (2001) A pH electrode based on melt-oxidized iridium oxide. J Electrochem Soc 148 (4):H29-H36. doi:10.1149/1.1353582

18. Yamanaka K (1989) Anodically electrodeposited iridium oxide films (AEIROF) from alkaline solutions for electrochromic display devices. Jpn J of Appl Phys 28:632-637 19. Wang M, Yao S (2003) Carbonate-Melt Oxidized Iridium Wire for pH Sensing. Electroanalysis 15 (20):1606-1615. doi:10.1002/elan.200302723 20. Wang M, Yao S, Madou M (2002) A long-term stable iridium oxide $\mathrm{pH}$ electrode. Sens Actuators, B 81:313-315. doi:10.1016/S0925-4005(01)00972-8 21. da Silva GM, Lemos SG, Pocrifka LA, Marreto PD, Rosario AV, Pereira EC (2008) Development of low-cost metal oxide $\mathrm{pH}$ electrodes based on the polymeric precursor method. Analytica chimica acta 616 (1):36-41. doi:10.1016/j.aca.2008.03.019 
22. Baur JE, Spaine TW (1998) Electrochemical deposition of iridium(IV) oxide from alkaline solutions of iridium(III) oxide. J Electroanal Chem 443 (2):208-216. doi:10.1016/S00220728(97)00532-9

23. Tarlov MJ, Semancik S, Kreider KG (1990) Mechanistic and response studies of iridium oxide pH sensors. Sens Actuators, B 1 (1-6):293-297. doi:10.1016/0925-4005(90)80218-O 24. Martinez CCM, Madrid RE, Felice CJ (2009) A pH sensor based on a stainless steel electrode electrodeposition with iridium oxide. IEEE Trans Educ 52:133-136. doi:10.1109/TE.2008.921451

25. Kakooei S, Ismail MC, Ari-Wahjoedi B (2013) An overview of pH sensors based on iridium oxide: fabrication and application. Int J Mat Sci Innovations 1 (1):62-72 26. O'Malley MJ, Woodward PM, Verweij H (2012) Production and isolation of pH sensing materials by carbonate melt oxidation of iridium and platinum. J Mater Chem 22 (16):77827790. doi:10.1039/c2jm16791c

27. O'Malley M (2008) $\mathrm{Li}+/ \mathrm{H}+$ ion exchanged Li2MO3 (M = Ir, Pt) and carbonated melt oxidized IrOx pH sensors (Master Thesis). PhD Thesis, The Ohio State University, Columbus, Ohio

28. Angst U, Vennesland $\varnothing$, Myrdal R (2009) Diffusion potentials as source of error in electrochemical measurements in concrete. Mater Struct 42 (3):365-375. doi:10.1617/s11527-008-9387-5

29. Pourbaix M (1974) Atlas of electrochemical equilibria in aqueous solutions. Pergamon Press 2nd ed.

30. Hüppauff M, Lengeler B (1993) Valency and structure of iridium in anodic iridium oxide films. J Electrochem Soc 140 (3):598-602. doi:10.1149/1.2056127

31. Juodkazytè J, Šebeka B, Valsiunas I, Juodkazis K (2005) Iridium anodic oxidation to $\operatorname{Ir}(\mathrm{III})$ and $\operatorname{Ir}(\mathrm{IV})$ hydrous oxides. Electroanalysis 17 (11):947-952.

doi:10.1002/elan.200403200

32. Trasatti S (1991) Physical electrochemistry of ceramic oxides. Electrochim Acta 36

(2):225-241. doi:10.1016/0013-4686(91)85244-2

33. Condition control and assessment of reinforced concrete structures exposed to corrosive environments (2011). State-of-art report, International Federation of Structural Concrete (FIB) Task group 5.8

34. Plusquellec G, Geiker MR, Lindgård J, Duchesne J, Fournier B, Weerdt KD (2017) Determination of the $\mathrm{pH}$ and the free alkali metal content in the pore solution of concrete: Review and experimental comparison. Cem Concr Res 96:13-26.

doi:10.1016/j.cemconres.2017.03.002

35. Yu M-Y, Lee J-Y, Chung C-W (2010) The application of various indicators for the estimation of carbonation and $\mathrm{pH}$ of cement based materials. J Test Eval 38 (5):534-540 
36. Khunthongkeaw J, Tangtermsirikul S, Leelawat T (2006) A study on carbonation depth prediction for fly ash concrete. Constr Build Mater 20 (9):744-753.

doi:10.1016/j.conbuildmat.2005.01.052

37. Sisomphon K, Franke L (2007) Carbonation rates of concretes containing high volume of pozzolanic materials. Cem Concr Res 37 (12):1647-1653.

doi:10.1016/j.cemconres.2007.08.014

38. Papadakis VG (2000) Effect of supplementary cementing materials on concrete resistance against carbonation and chloride ingress. Cem Concr Res 30 (2):291-299. doi:10.1016/S0008-8846(99)00249-5

39. Seguí Femenias Y, Angst U, Elsener B Durability monitoring of reinforced concrete. In: SMAR 2017 - International Conference on Smart Monitoring, Assessment and Rehabilitation of Civil Structures (submitted), Zürich, 2017.

40. Papadakis VG, Costas G. Vayenas, Fardis. MN (1991) Fundamental modeling and experimental investigation of concrete carbonation. ACI Mater J 88 (4):363-373.

doi:10.14359/1863

41. Kwon S-J, Song H-W (2010) Analysis of carbonation behavior in concrete using neural network algorithm and carbonation modeling. Cem Concr Res 40 (1):119-127.

doi:10.1016/j.cemconres.2009.08.022

42. Kashef-Haghighi S, Shao Y, Ghoshal S (2015) Mathematical modeling of CO2 uptake by concrete during accelerated carbonation curing. Cem Concr Res 67:1-10.

doi:10.1016/j.cemconres.2014.07.020

43. Gouda VK (1970) Corrosion and corrosion inhibition of reinforcing steel: I. Immersed in alkaline solutions. Br Corros J 5:198-203. doi:10.1179/000705970798324450

44. Angst U, Büchler M, Martin B, Schöneich HG, Haynes G, Leeds S, Kajiyama F (2016) Cathodic protection of soil buried steel pipelines - a critical discussion of protection criteria and threshold values. Mater Corros 67:1135-1142. doi:10.1002/maco.201608862 